\title{
Shortfalls to the Healthcare System and Recommendations During the COVID-19 Crisis
}

\author{
Sayed $\mathrm{A}^{1 *}$, Challa KT ${ }^{1}$, Akel $\mathrm{M}^{2}$, Massri $\mathrm{T}^{2}$, Snigdha $\mathrm{B}^{2}$, Ahmed $\mathrm{F}^{2}$ and Toor \\ $\mathbf{A}^{2}$ \\ ${ }^{1}$ Avalon University School of Medicine, Netherlands Antilles \\ ${ }^{2}$ St.James School of Medicine, St Vincent and the Grenadines
}

*Corresponding author: Abida Sayed, Avalon University School of Medicine, Curacao, Willemstad, Netherland Antilles, Tel: (416)287-9910; Email: naazanine@icloud.com

\section{Commentary}

Volume 4 Issue 1

Received Date: May 28, 2020

Published Date: June 17, 2020

DOI: $10.23880 /$ phoa-16000153

\section{Abstract}

The pandemic caused by the novel coronavirus disease 2019 (COVID) has left the healthcare system in havoc. With the rise in cases and overcrowding of health facilities, the overburdened demand on the healthcare system has left it with shortages of key provisions, personnel and intensive care units. Suggestions to consider for addressing these issues include increasing the workforce by recruitment of retired health professionals, use of mobile health units to tackle bed shortages, and handmade masks to combat against PPE shortages.

Keywords: Coronavirus; COVID-19; Delivery of Health Care; Mobile Health Units; Personal Protective Equipment

\section{Introduction}

The World Health Organization (WHO) declared COVID-19 a pandemic in early March 2020 in view of the exponential rise in prevalence and accelerated spread of a novel coronavirus known as coronavirus disease 2019 (COVID-19) [1]. Having originated from Wuhan China in early December 2019, it now has become a catastrophic public health concern [2]. Presently, there are greater than 1210956 confirmed cases world-wide with 67594 deaths [3]. This pandemic has drastically impacted care delivery as a result of insufficient provisions and equipment, as well as personnel and facility shortages [4]. Healthcare agencies are encountering urgent difficulties meeting with the rising demand for services with limited resources. This commentary discusses recommendations for new approaches to support the healthcare workforce in addressing shortages and maximum capacity of the healthcare system as well as efficient deliverance of care during this crisis.

\section{Critical Shortages in the Healthcare System}

The COVID-19 pandemic has pushed healthcare systems around the world into unprecedented times. Healthcare systems have struggled with increased patient levels requiring intensive care; reports have shown hospitals in need of life-saving equipment and manpower. Medical Association of Critical Care physicians claimed that the COVID-19 pandemic would strain the 29,000 intensive-caretrained physicians. New York hospitals have gone as far as mandating dermatologists and other specialty physicians in helping fight COVID-19 [5].

Recommendations: Recognizing this unparalleled situation, governments and institutions have moved to inhibit non-essential travel across borders and canceling many conferences and events to slow down the spread of infection and ease the stress on healthcare systems [6]. Due to the strain on healthcare systems, states such as New York and New Jersey have moved to increase their healthcare workforce by suspending red-tape requirements and making it easier for foreign medical graduates to join the struggle. Connecticut has requested retired healthcare workers return to the workforce while medical schools in New York have expedited graduation for fourth year students. With increasingly worrying trends of medical workers falling ill, 
these measures are to ensure an adequate workforce.

\section{Healthcare Systems at a Maximum Capacity}

Due to the current number of patients admitted to the ICU, linear and exponential models have calculated the number of patients needing ICU beds will exceed total ICU capacity [7]. Many hospitals worldwide are already facing shortages. It would be a great challenge for healthcare providers to deliver the best care to the patients when there is a clear shortage of ICU facilities, beds, and personal protective equipment (PPE). Along with ventilators and ICU beds, there is an extreme shortage of PPE for frontline healthcare workers that include masks, face shields, gloves, gowns, hand sanitizers, and respirators [8].

Recommendations: In order to contain the anticipated shortages faced by the healthcare system due to the COVID-19 virus, the federal government has moved to provide mobile health units in New York. Such field hospitals are located at the Javits Center and in Central Park; the former was built in a matter of days and accounts for an additional 4,000 beds $[9,10]$. Furthermore, providing a centralized emergency task force has ameliorated an already saturated health care system. Hospitals have been able to quell a pandemic of insurmountable portions through the use of established criteria. During this time, the CDC advised the government to put in place every measure, such as reinforcing public health measures of quarantine and self-isolation, to contain the virus [6]. Increasing laboratories testing along with the use of PPE early on could avert unintentional cross-contamination within the population. Additional resources include a cohesive collaborative effort of multinational emergency forces that would be vital in combating this pandemic.

\section{Support the Healthcare Workforce in Delivering High-Quality Care}

Some of the logistic problems confronted by healthcare workers in care deliverance include proper wearing of PPE and lack of healthcare equipment. The highest priority for all healthcare workers exposed to patients with respiratory symptoms is PPE. Barrier precautions are considered one of the most important preventive measures. Due to the limited availability of resources, such as N95 masks, it is important to highlight that protection is similarly achievable with regular surgical or medical masks applied to both the healthcare worker and patient. The CDC recommends that strict prioritization of the use of PPE be implemented to help ensure an adequate quantity remains for the treatment of high-risk patients [11]. In instances where face masks are not readily available, CDC recommends the use of face shields without masks, removing clinicians at high-risk of
COVID-19 from their clinical service temporarily, and the use of handmade masks made from bandanas and scarves.

The members of the healthcare workforce in the battle against COVID-19 have been under immense emotional pressure. Performing work duties with full protective gear can be tiresome and can result in injury and bruising if worn for long periods of time. This, along with the stress of higher risk of disease contraction and caring for co-workers who are infected can result in tremendous distress to healthcare workers. In Singapore, the Prime Minister has been playing an active role in boosting morale and showing their support to frontline workers by listening and personally addressing any concerns or challenges they may be facing to ensure that any difficulties are addressed immediately [12].

\section{Conclusion}

The Healthcare system's capacity to accommodate the strenuous events caused by COVID-19 has been pushed to the brink of collapse. To solve issues like healthcare workforce and equipment shortages, governments should pass regulations enabling the hire of more healthcare professionals. The frontline doctors, nurses, and other personnel are courageous heroes in this unanticipated battle against a complex and invisible enemy. It is the hope that the considerations in this brief report assist efforts to secure adequate health resources such as personnel, healthcare facilities, and equipment.

\section{Highlights}

- The healthcare disparities in our community have been highlighted due to the current pandemic, proper effective measures need to be taken to mitigate the healthcare crisis.

- In order for the health care workers to deliver proper care for the patients, proper protective equipment shortage should not be the constraint. Governments should work effectively to address the health care facilities' problems during these unprecedented times.

- Suggestions for mitigating these issues include increasing the workforce by recruitment of retired health professionals, use of mobile health units to combat bed shortages, and handmade masks to tackle PPE shortages.

\section{Declarations}

\section{Ethical Approval}

Not applicable as no live participants or samples were involved while producing this manuscript. 


\section{Competing Interests}

None declared.

\section{Funding}

This research did not receive any specific grant from funding agencies in the public, commercial, or not-for-profit sectors.

\section{References}

1. Centers for Disease Control and Prevention (2019) Coronavirus Disease 2019 (COVID-19) Situation Summary. Cases in the US.

2. Meng L, Hua F, Bian Z (2020) Coronavirus Disease 2019 (COVID-19): Emerging and Future Challenges for Dental and Oral Medicine. J Dent Res 99(5): 481-487.

3. (2020) Coronavirus disease 2019 (COVID-19): Situation Report-75. World Health Organization, pp: 1-11.

4. Xie J, Tong Z, Guan Z, Du B, Qui H, et al. (2020) Critical care crisis and some recommendations during the COVID-19 epidemic in China, Intensive Care Med 46: 837-840.

5. (2020) With Virus Surge, Dermatologists and Orthopedists Are Drafted for the E.R. The New York
Times.

6. Adams JG, Walls MR (2020) Supporting the Health Care Workforce during the COVID-19 Global Epidemic. JAMA 323(15): 1439-1440.

7. Grasselli G, Presenti A, Cecconi M (2020) Critical Care Utilization for the COVID-19 Outbreak in Lombardy, Italy: Early Experience and Forecast During an Emergency Response. JAMA 323(16): 1545-1546.

8. Ranney LM, Griffeth V, Jha KA (2020) Critical Supply Shortages-The Need for Ventilators and Personal Protective Equipment during the COVID-19 Pandemic. N Engl J Med 382: 18.

9. Lombroso D (2020) The Surreality of Central Park's Field Hospital. The Atlantic.

10. (2020) Inside the Javits Center: New York's militarized, makeshift hospital. The Washington Post.

11. Livingston E, Desai A, Berkwits M (2020) Sourcing Personal Protective Equipment during the COVID-19 Pandemic. JAMA 323(19): 1912-1914.

12. Wong JEL, Leo YS, Tan CC (2020) COVID-19 in SingaporeCurrent Experience Critical Global Issues That Require Attention and Action, JAMA 323(13): 1243-1244. 